\title{
Circulating Endothelial Giant Cells Permissive for Human Cytomegalovirus (HCMV) Are Detected in Disseminated HCMV Infections with Organ Involvement
}

\author{
Elena Percivalle, * M. Grazia Revello, " Luca Vago, ${ }^{*}$ Fulvia Morini, ${ }^{*}$ and Giuseppe Gerna * \\ *Virus Laboratory, Institute of Infectious Diseases, University of Pavia, Istituto Ricovero Cura Carattere Scientifico Policlinico S. \\ Matteo, 27100 Pavia, Italy; and $\ddagger^{V}$ Department of Pathology, L. Sacco Hospital, University of Milan, 20100 Milan, Italy
}

\begin{abstract}
Giant cells fully permissive for human cytomegalovirus (HCMV) were found to circulate, at a variable proportion, in peripheral blood of 21 out of 25 immunocompromised patients with disseminated HCMV infection. Circulating endothelial giant cells (EGC) were identified by a specific monoclonal antibody of endothelial origin and shown to express immediateearly, early, and late viral proteins. Immunostaining patterns of different viral proteins were comparable to those detected in vitro in cultured human umbilical vein endothelial cells. EGC counts $>10$ were associated with high levels $(>100)$ of HCMV viremia and antigenemia, as well as with an overt clinical syndrome in transplanted patients, and to an untreated long lasting organ localization in AIDS patients. On the other hand, EGC counts were $<10$ during disseminated HCMV infections of both transplant recipients with no apparent organ syndrome and AIDS patients with recent organ involvement. In tissue sections from AIDS patients, infected endothelial cells were found to progressively enlarge till detaching from the small vessel wall and entering blood stream. HCMV-infected EGC represent a new systemic parameter suitable for the diagnosis of HCMV organ involvement and for the study of the pathogenesis of disseminated infections. (J. Clin. Invest. 1993. 92:663670.) Key words: heart transplant $\bullet$ AIDS • antigenemia • viremia $\bullet$ antivirals
\end{abstract}

\section{Introduction}

Disseminated human cytomegalovirus (HCMV) ${ }^{1}$ infections occur at a high rate in immunosuppressed, namely AIDS, patients (1). Such infections are diagnosed by determination of HCMV antigenemia (i.e., detection of HCMV antigens, and namely pp65, in PMN and mononuclear [MN] leukocytes [24]), and viremia (i.e., HCMV isolation from PMN and MN [5,

Address correspondence to Prof. G. Gerna, Virus Laboratory, Institute of Infectious Diseases, University of Pavia, IRCCS, Policlinico S. Matteo, 27100 Pavia, Italy.

Received for publication 13 November 1993 and in revised form 19 March 1993.

1. Abbreviations used in this paper: APAAP, alkaline phosphatase-antialkaline phosphatase; CSF, cerebrospinal fluid; ECG, endothelial giant cells; HCMV, human cytomegalovirus; HLTR, heart-lung transplant recipients; HLTR, heart transplant recipients; HUVEC, human umbilical vein endothelial cells; $M / M$, monocyte/macrophages; vWf, von Willebrand factor.

J. Clin. Invest.

(c) The American Society for Clinical Investigation, Inc.

0021-9738/93/08/0663/08 \$2.00

Volume 92, August 1993, 663-670
6]). Both antigenemia and viremia have been quantitated, and a correlation between high levels of these two parameters and presence or appearance of clinical symptoms has been observed (7). On the other hand, organ localization of HCMV infection can only be diagnosed by pathologic and virologic examination of bioptic samples. Although organ localization is the consequence of a systemic infection, the sole detection of virus or viral components in blood is not per se sufficient to attribute an etiologic role to HCMV in the pathogenesis of organ syndromes. In addition, in a minor number of cases, HCMV organ localization is not associated to presence of virus in blood.

This report describes the detection of a new marker of HCMV infection in blood of immunosuppressed patients, consisting of HCMV-infected circulating endothelial giants cells (EGC), which are found in greater proportions concomitantly with an organ syndrome.

\section{Methods}

Patients. 10 heart or heart-lung transplant recipients (HTR or HLTR) and 15 AIDS patients were included in the study. Of these, five HTR and two HLTR, as well as three AIDS patients underwent clinical and virologic follow up for HCMV infection. Patients undergoing antiviral treatment received either ganciclovir $(10 \mathrm{mg} / \mathrm{kg}$ per d) or foscarnet $(180 \mathrm{mg} / \mathrm{kg}$ per $\mathrm{d}$ ) as induction treatment. Quantitation of HCMV in blood was achieved by sequential determination of pp65-antigenemia, viremia, and count of HCMV-infected EGC.

pp65-Antigenemia. Quantitation of pp65-antigenemia was achieved by using a fluorescence microscope to count the number of PMN positive for HCMV pp $65 / 2 \times 10^{5}$ cells examined on cytospin preparations stained according to a recently reported procedure (4).

Viremia. Viremia was quantified by inoculating $2 \times 10^{5} \mathrm{PMN}$ onto human embryonic lung fibroblast cell cultures according to the shell vial technique and then counting the number of fibroblasts positive for HCMV immediate-early antigen p $72,16-24 \mathrm{~h}$ postinfection (5). A significant correlation between levels of pp65-antigenemia and viremia has been previously reported (5).

Virus isolation. Conventional virus isolation from blood leukocytes and other clinical samples including bioptic specimens was performed on human embryonic lung fibroblast cell cultures after appearance of cytopathic effect within $2 \mathrm{wk}$ postinfection. Negative cultures were blindly passaged for another 2-wk period. HCMV was identified as reported (5).

Cytospin preparations of $M N$ for detection of EGC. Ficoll-separated MN were adjusted to a concentration of $2 \times 10^{6}$ cells $/ \mathrm{ml}$. Cytospin preparations were obtained by centrifugation of $2 \times 10^{5}$ cells onto glass slides ( $100 \mu \mathrm{l} / \mathrm{slide}$ ) at $90 \mathrm{~g}$ for $3 \mathrm{~min}$ by using a cytocentrifuge (Cytospin 2; Shandon Southern Products Ltd. Runcorn, United Kingdom). Slides were air dried for $\geq 30 \mathrm{~min}$ and then fixed. To obtain better immunostaining patterns, cells were fixed using 5\% paraformaldehyde and then permeabilized with $0.5 \%$ NP-40 according to a reported procedure (4). After air drying for $\geq 20 \mathrm{~min}$, slides were ready for staining or storage at $-80^{\circ} \mathrm{C}$.

Endothelial cells. Human umbilical vein endothelial cells (HUVEC) were isolated according to a reported procedure (8). Cultures were propagated in endothelial cell growth medium, consisting of 
M-199 supplemented with $20 \%$ FCS, $1 \%$ endothelial cell culture supernatant (9), and $10 \mathrm{U} / \mathrm{ml}$ sodium heparin. Growing surfaces for HUVEC were pretreated with $0.2 \%$ gelatin. Cultures at passage 3 were used in the reported experiments. HUVEC were infected using a multiplicity of infection of $1-5$ of the reference strain AD 169 previously passaged onto human embryonic fibroblast cell cultures.

Monoclonal antibodies. Two mAbs were used for phenotype identification of EGC: one, referred to as PAL-E (Sera-lab, Crawly Down, Sussex, United Kingdom), specific for endothelium of capillaries, venules and medium-sized and small veins, but neither recognizing medium-sized and small arteries and arterioles nor megakaryocytes and platelets (10); the other one specific for von Willebrand factor (vWf)(M616; Dako A/S, Glostrup, Denmark). The same two mAbs were used for immunostaining of HCMV-infected HUVEC, as well as tissue sections. Identification of HCMV proteins present in EGC, as well as in HUVEC used the following HCMV-specific mAbs developed in the laboratory: (a) mAbs to the major immediate-early protein p72 (11); (b) mAbs to the lower matrix phosphoprotein pp65 (11); (c) mAbs to the major DNA-binding protein p52 (12); a single mAb to a late viral protein, p150 (5). An mAb recognizing an early $\mathrm{HCMV}$ antigen (M757, Dako A/S) (13), as well as the mAb to p150 were used for tissue sections.

Immunostaining procedure. The immunofluorescence technique was used routinely, while the immunoperoxidase method was often done in parallel, according to a recently reported procedure (4). For the immunofluorescence method, cytospin preparations were first reacted for $30 \mathrm{~min}$ at $37^{\circ} \mathrm{C}$ with optimal dilutions of different $\mathrm{mAbs}$ and then, after washings, with a fluorescein-conjugated $F\left(a b^{\prime}\right)_{2}$ fragment goat anti-mouse IgG (Organon Teknika, Cappel Laboratories, West Chester, PA) optimally diluted in PBS- $0.0005 \%$ Evans blue. The immunoperoxidase method followed the same procedure, using a peroxidase-conjugated $\mathrm{F}\left(\mathrm{ab}^{\prime}\right)_{2}$ fragment goat anti-mouse IgG (Cappel Laboratories). After the second step of the reaction, the chromogensubstrate solution (diaminobenzidine- $\mathrm{H}_{2} \mathrm{O}_{2}$ in $0.05 \mathrm{M}$ Tris [pH7.6]) was added for $5 \mathrm{~min}$ at room temperature. Finally, in both procedures, slides were mounted and positive EGC were counted under an ultraviolet or a light microscope, respectively. Details of other immunostaining techniques such as alkaline phosphatase-antialkaline phosphatase (APAAP) have been previously reported (4). Histologic and immunohistochemical procedures for staining of deparaffinized tissue sections were performed according to standard methods.

Double immunostaining of EGC for HCMV and endothelial cell antigen was performed by first reacting formalin-fixed cells with a guinea pig immune serum to HCMV capsid antigen (developed in the laboratory), which was detected by the IPA technique (brown nuclear staining). Then, same cell preparations were reacted with $\mathrm{mAb}$ PAL-E, which was revealed by the APAAP procedure (red cytoplasmic granular staining).

\section{Results}

Detection of HCMV-infected EGC in immunocompromised patients. The presence of HCMV-infected EGC (Fig. $1 A$ ) in the peripheral blood MN fraction from HTR/HLTR and AIDS patients was observed during a disseminated HCMV infection. Tables I and II report quantitative levels of EGC, as well as of pp65-antigenemia and viremia detected in 10 HTR/HLTR and in 15 AIDS patients, respectively, along with HCMV clinical symptoms or organ syndromes. In Table I, patients 3 and 8 with levels of EGC $>10$ were both affected by a symptomatic HCMV gastritis (diagnosed by virus isolation from and presence of inclusion-bearing epithelial cells in gastric biopsy), whereas the remaining eight patients with no clinical symptoms related to an organ syndrome showed low $(<5)$ or negative (patients 6 and 9) levels of EGC, either in the presence or absence of systemic clinical symptoms. Thus, presence of an
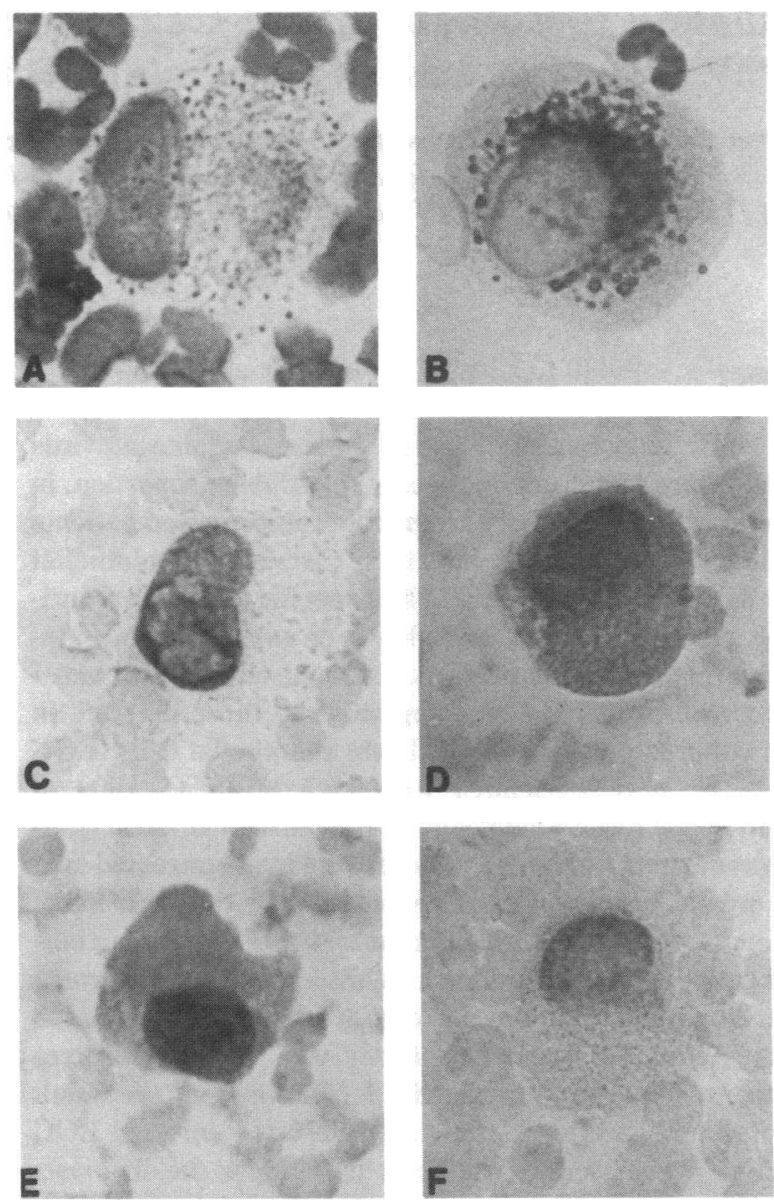

Figure 1. Circulating giant cells, stained by $(A)$ Giemsa and $(B-F)$ immunoperoxidase for the following HCMV antigens: $B$, pp65; $C$, p 72; $D$ and $E$, p52; and $F, \mathrm{p} 150$. For size comparison, note, in $B$, the presence of a pp65-positive PMN nucleus. $\times 1,000$.

organ syndrome rather than levels of pp65-antigenemia and/ or viremia appeared to be associated with a number of EGC $>10$. In Table II, 13 out of 15 AIDS patients with HCMV retinitis and/or other HCMV organ syndromes, showed presence of a variable number of EGC in peripheral blood. Patients 1 and 2 showing the highest number of EGC suffered from a progressive HCMV retinitis which, undiagnosed, was not treated for several weeks until virologic examination. In addition, patient 1 was affected by HCMV polyradiculomyelitis (diagnosed by pp65 detection in cerebrospinal fluid-CSFPMN) and by a maxillary sinusitis (diagnosed by virus isolation from sinus lavage fluid). Patients 4 and 7 were examined the second day of ganciclovir treatment, when EGC were still detected and viremia was already negative. All the remaining patients with a number of EGC of 0-8 had a recently diagnosed retinitis and had not yet received antiviral treatment. Thus, in AIDS patients untreated long-lasting organ syndromes appeared to be associated with a number of EGC $>10$, whereas low $(<10)$ or negative levels of EGC were found in patients with a recent organ involvement.

Identification of the endothelial origin of EGC. Since it is well known that endothelial cells represent a primary target of HCMV infection in vivo both in disseminated infections as well as in organ localizations, EGC were reacted with an $\mathrm{mAb}$ 
Table I. Detection of Circulating EGC in Heart and Heart-Lung Transplant Recipients with Disseminated HCMV Infection

\begin{tabular}{|c|c|c|c|c|c|c|}
\hline \multirow{2}{*}{$\begin{array}{l}\text { Patient } \\
\text { number }\end{array}$} & \multirow{2}{*}{$\begin{array}{c}\text { Type of organ } \\
\text { transplant, and } \\
\text { HCMV infection* }\end{array}$} & \multirow{2}{*}{$\begin{array}{l}\text { Days after } \\
\text { transplant }\end{array}$} & \multicolumn{3}{|c|}{ HCMV quantification in blood ${ }^{\ddagger}$} & \multirow{2}{*}{$\begin{array}{c}\text { HCMV } \\
\text { symptoms/organ } \\
\text { syndrome }\end{array}$} \\
\hline & & & pp65-Ag & Viremia & EGC & \\
\hline 1 & HT, R & 17 & 75 & 37 & 1 & None \\
\hline 2 & HT, R & 40 & 431 & 81 & 3 & None \\
\hline 3 & HT, R & 35 & 800 & 170 & 49 & Gastritis \\
\hline 4 & HT, R & 24 & 900 & 152 & 1 & Fever \\
\hline 5 & HLT, R & 35 & 295 & 121 & 1 & Fever \\
\hline 6 & $\mathrm{HT}, \mathrm{R}$ & 41 & 16 & 4 & 0 & None \\
\hline 7 & HT, R & 79 & 600 & 206 & 1 & None \\
\hline 8 & HT, P & 36 & $>1,000$ & 350 & 15 & Gastritis, fever \\
\hline 9 & HT, R & 46 & 11 & 4 & 0 & None \\
\hline 10 & HLT, R & 42 & 657 & 167 & 1 & Fever \\
\hline
\end{tabular}

${ }^{*} \mathrm{HT}$, heart transplant; HLT, heart-lung transplant; R, recurrent; P, primary. ${ }^{\ddagger} \mathrm{HCMV}$ was quantified in blood by determination of: $(a)$ pp65$\mathrm{Ag}$, pp65-antigenemia; i.e. the number of PMN positive for pp65/2 $\times 10^{5} \mathrm{PMN}$ examined (4); $(b)$ viremia; i.e., the number of PMN yielding infectious virus in human embryonic lung fibroblast cell cultures $/ 2 \times 10^{5} \mathrm{PMN}$ inoculated (5); and $(c) \mathrm{EGC}$; i.e. the number of HCMV-infected $\mathrm{EGC} / 2 \times 10^{5} \mathrm{MN}$ examined.

(PAL-E) specifically recognizing an endothelial cell protein, as well as with a mAb specific for vWf. As shown in Fig. 2, $A$ and $B$, the staining pattern obtained using PAL-E and the APAAP method was comparable in both EGC and HUVEC. Similar results were obtained using mAb to vWf. On this basis, EGC were considered most likely to be of endothelial origin.

Detection of HCMV immediate-early, early, and late structural antigens in EGC. Level of HCMV replication in EGC was determined by reacting multiple $\mathrm{MN}$ cytospin preparations with high, low, and negative number of EGC, with mAbs developed in the laboratory and previously characterized to react with the major immediate-early protein $\mathrm{p} 72$, the major DNA binding protein $\mathrm{p} 52$, the early structural lower matrix phos-

Table II. Detection of Circulating EGC in AIDS Patients with Disseminated HCMV Infection

\begin{tabular}{|c|c|c|c|c|}
\hline \multirow{2}{*}{$\begin{array}{l}\text { Patient } \\
\text { number }\end{array}$} & \multicolumn{3}{|c|}{ HCMV quantification in blood* } & \multirow{2}{*}{$\begin{array}{l}\text { HCMV organ } \\
\text { syndrome }\end{array}$} \\
\hline & pp65-Ag & Viremia & EGC & \\
\hline 1 & $>1,000$ & 436 & 24 & $\begin{array}{l}\text { Polyradiculomyelitis, } \\
\text { retinitis, maxillary sinusitis }\end{array}$ \\
\hline 2 & 900 & 80 & 28 & Retinitis \\
\hline 3 & 600 & 400 & 6 & Retinitis, maxillary sinusitis \\
\hline 4 & 398 & $0^{\ddagger}$ & 3 & Retinitis \\
\hline 5 & $>1,000$ & 400 & 5 & Retinitis \\
\hline 6 & 538 & 300 & 1 & Retinitis \\
\hline 7 & 303 & $0^{\ddagger}$ & 6 & Interstitial pneumonitis \\
\hline 8 & 276 & 40 & 7 & Retinitis \\
\hline 9 & 90 & 40 & 5 & Retinitis \\
\hline 10 & 110 & 35 & 5 & Retinitis \\
\hline 11 & 54 & 10 & 6 & Retinitis \\
\hline 12 & $>1,000$ & 200 & 8 & Retinitis \\
\hline 13 & 58 & 17 & 0 & Retinitis \\
\hline 14 & 118 & 3 & 1 & Retinitis \\
\hline 15 & 114 & 3 & 0 & Retinitis \\
\hline
\end{tabular}

* See footnote ${ }^{\ddagger}$ of Table I. ${ }^{\ddagger}$ Patients 4 and 7 were examined on the second day of ganciclovir treatment. phoprotein pp65 and the major capsid protein p150. As shown in Fig. 1, $C-F$, p72, p52 and p150 were consistently detected in EGC nuclei with staining patterns resembling those commonly observed in HCMV-infected human embryonic lung fibroblast cell cultures. On the other hand, pp65 was predominantly detected inside the cytoplasm of EGC (Fig. $1 B$ ), again according to a staining pattern well known in infected cultured human fibroblasts (11). In parallel, the same mAbs were tested on HCMV-infected HUVEC cultured in vitro. As shown in Fig. 2, $C-F$, the same staining patterns observed in EGC were found in HCMV-infected HUVEC. Double immunostaining of EGC for HCMV (brown nucleus) and endothelial antigen (red cytoplasm) is shown in Fig. 3, $A$ and $B$.

Correlation between HCMV organ syndromes and EGC. When HTR/HLTR underwent follow up, it was observed that levels of EGC were never $>5$ in patients with a clinically asymptomatic HCMV infection (Table III, patients 2, 7, and 9). The same finding was obtained in transplanted patients with a symptomatic yet clinically uncomplicated (absence of organ syndromes) HCMV infection (Table III, patients 5 and $10)$. In both groups of patients, EGC were detected concomitantly with the highest levels of antigenemia and viremia. On the other hand, when HCMV infection was associated to a HCMV organ syndrome, the EGC count was variably $>5$ ( Table III, patients 3 and 8). The peak number of EGC was reached 5-10 d after onset of organ localization symptoms, corresponding to peak levels of antigenemia and viremia. Antiviral treatment with either ganciclovir or foscarnet led to disappearance of EGC, as well as viremia and antigenemia, together with resolution of clinical symptoms.

Virologic follow up of three AIDS patients with HCMV organ syndromes showed that EGC, viremia and antigenemia were progressively increasing in number, whereas antiviral treatment induced EGC to disappear from blood in a few days (Table IV, patients 1-3). Viremia became negative a few days earlier than EGC in two of the three patients examined. However, reappearance of viremia, caused by emergence of a ganciclovir-resistant strain, was not associated to reappearance of EGC in blood ( Table IV, patient 3). Interestingly, a cerebrospinal fluid (CSF) sample was also available, at the time of first 

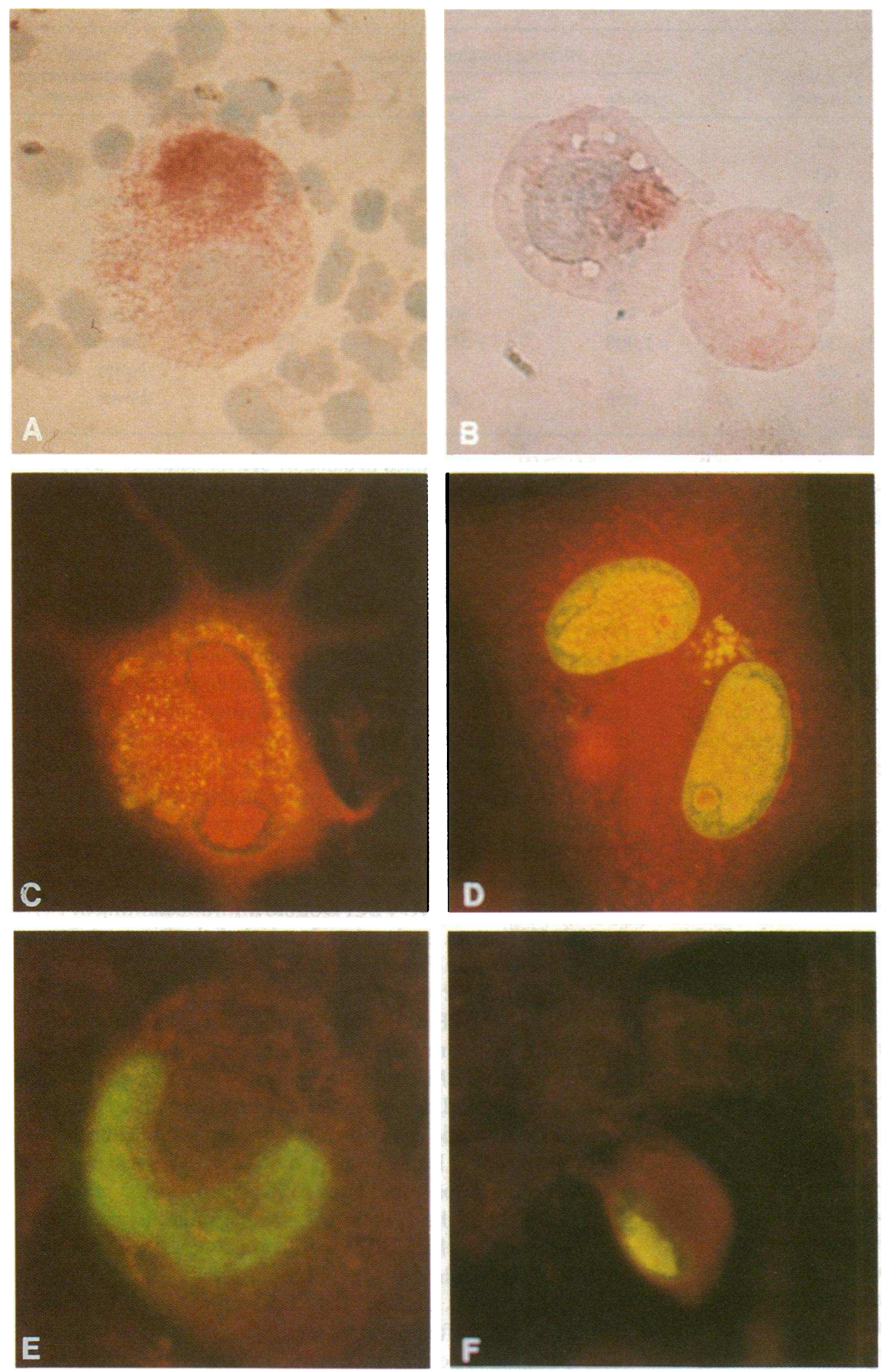

Figure 2. A circulating giant cell $(A)$ and a HUVEC from a primary culture $(B)$, as stained by monoclonal antibody PAL-E specific for endothelial cells and the APAAP procedure (arrows indicate areas of strongest staining). $(C-F)$ HUVEC stained by immunofluorescence for the following HCMV antigens: $C$, pp65; $D, \mathrm{p} 72 ; E, \mathrm{p} 52 ;$ and $F$, p150. $\times 1,000$.

blood collection, in patient 1 (Table IV). While the number of pp65-positive PMN in blood and CSF was comparable $(\sim 800)$, there were only two EGC in blood as compared to 50 in CSF. After ganciclovir treatment, EGC disappeared from CSF, whereas a few pp65-positive PMN persisted both in blood and CSF. Thus, EGC appeared to accumulate in CSF because of nervous system involvement.

Apparent identity of EGC with HCMV-infected endothelial cells detaching from wall of small vessels in histologic sections. Multiple observations performed on bioptic or autoptic tissues according to routine histologic procedures showed that endo- thelial cells of capillary or small vessels are primary targets of viral infection in organ localizations of HCMV infection. Endothelial cells enlarge with progression of HCMV infection and, when nuclear inclusion bodies are detected, cells round up and detach from wall inside the vessel lumen (Fig. 4, $A$ and $B$ ). Immunocytochemical identification of the phenotype of these cells with $\mathrm{mAb}$ to $\mathrm{vWf}$ showed that they are true endothelial cells infected by HCMV (Fig. 5). In addition, detection of viral proteins present inside the cells with a $\mathrm{mAb}$ recognizing an early HCMV antigen and a mAb for a late viral protein (data not reported), showed that both early and late viral antigens 
Table III. EGC Detection during Virologic and Clinical Follow Up of HCMV Infection in Heart and Heart-Lung Transplant Recipients

\begin{tabular}{|c|c|c|c|c|c|c|c|}
\hline \multirow{2}{*}{$\begin{array}{l}\text { Patient } \\
\text { number }\end{array}$} & \multirow[b]{2}{*}{$\begin{array}{l}\text { Age (yr), organ transplant, type, and clinical } \\
\text { course of HCMV infection* }\end{array}$} & \multirow[b]{2}{*}{$\begin{array}{l}\text { Days after } \\
\text { transplant }\end{array}$} & \multicolumn{3}{|c|}{ HCMV quantification in blood ${ }^{\ddagger}$} & \multirow{2}{*}{$\begin{array}{c}\text { HCMV } \\
\text { clinical } \\
\text { symptoms }\end{array}$} & \multirow[b]{2}{*}{$\begin{array}{l}\text { Antiviral } \\
\text { treatment }\end{array}$} \\
\hline & & & pp65-Ag & Viremia & EGC & & \\
\hline \multirow[t]{6}{*}{9} & $53, \mathrm{HT}, \mathrm{R}$, asymptomatic & 18 & 0 & 0 & 0 & - & - \\
\hline & & 32 & 2 & 0 & 0 & - & - \\
\hline & & 39 & 10 & 4 & 0 & - & - \\
\hline & & 46 & 11 & 4 & 0 & - & - \\
\hline & & 49 & 7 & 2 & 0 & - & - \\
\hline & & 53 & 0 & 0 & 0 & - & - \\
\hline \multirow[t]{12}{*}{2} & $54, \mathrm{HT}, \mathrm{R}$, asymptomatic & 16 & 0 & 0 & 0 & - & - \\
\hline & & 23 & 1 & 0 & 0 & - & - \\
\hline & & 26 & 13 & 5 & 0 & - & - \\
\hline & & 33 & 21 & 8 & 0 & - & - \\
\hline & & 37 & 41 & 3 & 0 & - & - \\
\hline & & 40 & 431 & 81 & 3 & - & - \\
\hline & & 44 & 443 & 31 & 5 & - & - \\
\hline & & 46 & 400 & 2 & 4 & - & - \\
\hline & & 48 & 300 & 1 & 3 & - & - \\
\hline & & 51 & 79 & 0 & 2 & - & - \\
\hline & & 54 & 21 & 0 & 1 & - & - \\
\hline & & 58 & 0 & 0 & 0 & - & - \\
\hline \multirow[t]{11}{*}{7} & $63, \mathrm{HT}, \mathrm{R}$, asymptomatic & 16 & 0 & 0 & 0 & - & - \\
\hline & & 23 & 3 & 1 & 0 & - & - \\
\hline & & 26 & 20 & 4 & 0 & - & - \\
\hline & & 40 & 35 & 8 & 0 & - & - \\
\hline & & 44 & 75 & 54 & 0 & - & - \\
\hline & & 73 & 420 & 70 & 0 & - & - \\
\hline & & 77 & 650 & 50 & 0 & - & - \\
\hline & & 79 & 600 & 206 & 1 & - & - \\
\hline & & 84 & 700 & 19 & 0 & - & - \\
\hline & & 98 & 10 & 0 & 0 & - & - \\
\hline & & 121 & 0 & 0 & 0 & - & - \\
\hline \multirow[t]{7}{*}{5} & 50, HLT, R, symptomatic (fever) & 13 & 0 & 0 & 0 & - & - \\
\hline & & 27 & 25 & 3 & 0 & - & - \\
\hline & & 35 & 295 & 121 & 1 & + & GCV \\
\hline & & 36 & 400 & 0 & 0 & - & GCV \\
\hline & & 38 & 21 & 0 & 0 & - & GCV \\
\hline & & 41 & 2 & 0 & 0 & - & GCV \\
\hline & & 48 & 0 & 0 & 0 & - & GCV \\
\hline \multirow[t]{12}{*}{10} & 29, HLT, P, symptomatic (fever) & 10 & 0 & 0 & 0 & - & - \\
\hline & & 14 & 1 & 0 & 0 & - & - \\
\hline & & 17 & 9 & 3 & 0 & - & - \\
\hline & & 21 & 36 & 15 & 0 & - & - \\
\hline & & 28 & 75 & 52 & 0 & - & - \\
\hline & & 32 & 95 & 44 & 0 & - & - \\
\hline & & 35 & 155 & 72 & 0 & - & - \\
\hline & & 39 & 550 & 133 & 1 & + & - \\
\hline & & 42 & 657 & 167 & 1 & + & GCV \\
\hline & & 45 & 650 & 0 & 0 & + & GCV \\
\hline & & 48 & 480 & 0 & 0 & - & GCV \\
\hline & & $56-61$ & 0 & 0 & 0 & - & GCV \\
\hline \multirow[t]{8}{*}{3} & 32, HT, R, complicated (HCMV gastritis, & 11 & 0 & 0 & 0 & - & - \\
\hline & thrombocytopenia) & 15 & 1 & 0 & 0 & - & - \\
\hline & & 20 & 3 & 1 & 0 & - & - \\
\hline & & 25 & 42 & 5 & 0 & + & - \\
\hline & & 32 & 289 & 57 & 1 & + & - \\
\hline & & 35 & 800 & 170 & 49 & + & PFA \\
\hline & & $40-50$ & 0 & 0 & 0 & - & PFA \\
\hline & & $51-61$ & 0 & 0 & 0 & - & - \\
\hline 8 & 28, HT, P, complicated (HCMV gastritis, & 20 & 0 & 0 & 0 & - & - \\
\hline & fever, leukopenia) & 31 & 109 & 111 & 1 & + & - \\
\hline & & 34 & 800 & 213 & 2 & + & - \\
\hline & & 36 & $>1,000$ & 350 & 15 & + & PFA \\
\hline & & 38 & 191 & 2 & 1 & + & PFA \\
\hline & & 41 & 0 & 0 & 0 & - & PFA \\
\hline & & $45-56$ & 0 & 0 & 0 & - & PFA \\
\hline & & $57-90$ & 0 & 0 & 0 & - & - \\
\hline
\end{tabular}

* HCMV infections were classified as asymptomatic in the absence of clinical symptoms, symptomatic when systemic symptoms were present, and complicated when local symptoms suggesting organ involvement were apparent. Symptoms are reported in parentheses. ${ }^{\ddagger}$ See footnote ${ }^{\ddagger}$ of Table I.,- Absent; + , present; - , no treatment; GCV, ganciclovir; PFA, foscarnet. 


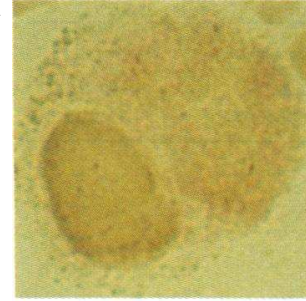

A

Figure 3. Double immunostaining of EGC for HCMV, using a guinea pig immune serum to a capsid antigen and the immunoperoxidase technique (brown nucleus), and for endothelial antigen, using $\mathrm{mAb}$ PAL-E and the APAAP procedure (red cytoplasm). $\times 1,000$.

are present, suggesting a full viral replication cycle. However, only a minor part of HCMV-infected EGC reacted strongly with $\mathrm{mAb}$ to vWf. This was most likely caused by the loss of vWf in HCMV-infected endothelial cells, as reported in in vitro studies (14). Thus, these findings support the view that EGC are cells of endothelial origin circulating in peripheral blood after detachment from the vessel wall resulting from HCMV infection.

\section{Discussion}

HCMV-infected EGC have been identified in the peripheral blood of immunocompromised patients with systemic HCMV infection and are often detected concomitantly with a HCMV organ syndrome. At the moment, these results, given the limited number of patients examined, are only preliminary and their clinical significance must be confirmed on a more extended series of patients.

EGC represent a new marker of HCMV infections, which appears highly interesting from a pathogenetic standpoint. It has been reported that endothelial cells are a common target of HCMV infection in vivo, regardless of the organ involved (15, 16), and that they might represent a site of HCMV latency in immunocompetent subjects (17-19). This hypothesis seems to be supported by recent data obtained using the polymerase chain reaction, which showed the presence of HCMV DNA in blood vessels of most HCMV-seropositive subjects $(20,21)$. It is well known that in immunosuppressed, and namely AIDS patients with disseminated HCMV infection, HCMV inclusion-bearing endothelial cells are often detected in multiple organs $(22,23)$.

The new finding reported in this paper is that HCMV-infected endothelial cells progressively enlarge till they detach from the vessel wall and enter the blood stream. EGC detected in peripheral blood show advanced CPE and often undergo initial lysis with frequent cytoplasmic shedding. Identification of the endothelial phenotype and detection of early and late viral antigens in both EGC and HCMV-infected cells of small vessel walls support the hypothesis that EGC are the same cells observed in histologic sections.

It seems reasonable to hypothesize that in vivo endothelial cells may be infected by circulating infected PMN and monocyte/macrophages $(M / M)$. While it is well known that HCMV can be isolated from $M / M$ as well as from PMN (6, $24)$, it is commonly recognized that infectious virus and viral material detected in PMN of immunocompromised patients are mostly uptaken by phagocytosis (25), although HCMV early replicative events do seem to occur in $\operatorname{PMN}(6,26)$. This assumption mainly applies to the HCMV lower matrix phosphoprotein pp65 detected in nuclei of infected PMN. The same event can occur in $\mathbf{M} / \mathbf{M}$ which, however, have been shown to become permissive for HCMV replication in vitro when differentiation into macrophages occurs (27) or macrophage treatment with therapeutic levels of hydrocortisone is performed (28).

Table IV. EGC Detection during Virologic and Clinical Follow Up of HCMV Infection in AIDS Patients

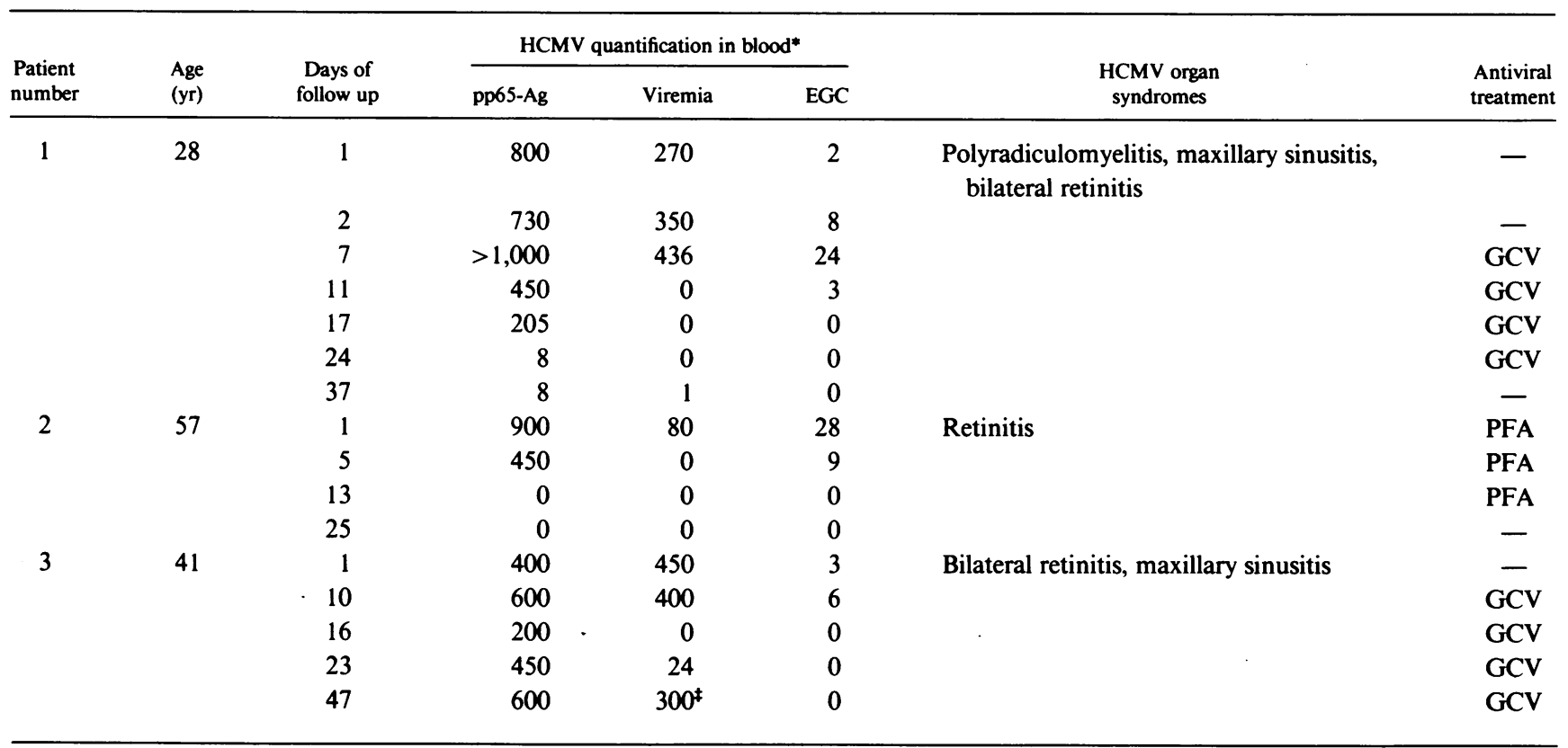

${ }^{*}$ See footnote ${ }^{\ddagger}$ of Table I. ${ }^{\ddagger}$ Emergence of ganciclovir resistance. -, No treatment; GCV, ganciclovir; PFA, foscarnet. 

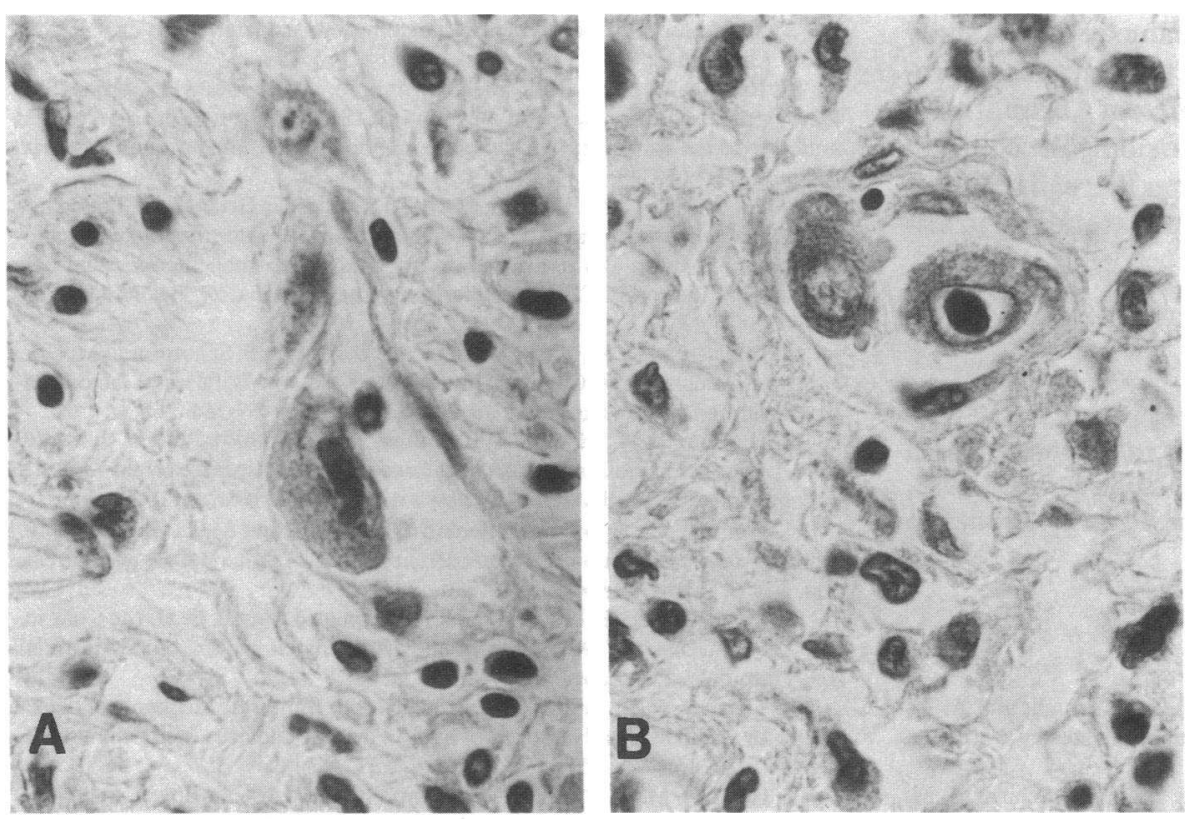

Figure 4. Endothelial giant cells detaching from the small vessel wall in prostatic tissue sections from an AIDS patient. $(A)$ Giant cell resembling that of Fig. $1 A$; B, two giant cells at different stages of HCMV infection. H\&E staining. $\times 800$.
When endothelial cells are infected, new progeny virus may infect contiguous cells, while the originally infected cells at late stages of infection enter the blood stream, thus becoming detectable in peripheral blood. EGC displaying advanced CPE are likely to undergo lysis during circulation, thus disseminating infectious virus and viral material that can be phagocytized by $P M N$ and $M / M$, which, in turn, can infect other body districts, including endothelium. Although, endothelial cells are heavily infected in every HCMV localization, the sole presence of virus inside endothelial cells is not sufficient to define a HCMV organ syndrome, unless parenchymal cells are involved and $\mathrm{MN}$ infiltrates are found.

From a diagnostic standpoint, detection of EGC may provide a circulating marker of HCMV organ localization. The rapid disappearance of EGC from blood within a few days of treatment suggests that timely initiation of specific antiviral treatment might resolve organ localization at an early stage, thus preventing massive organ involvement. The detection of a fair number of EGC in all patients examined with a clinically overt organ syndrome seems to suggest, albeit preliminarily, an association between EGC and organ involvement. In AIDS patients with HCMV retinitis, the EGC number was low in most patients examined. This seems to be in agreement with a recent report showing that levels of circulating HCMV DNA in blood leukocytes is relatively low in AIDS patients with HCMV retinitis as compared to patients with HCMV visceral organ involvement (29). These results may partly find their biological basis in the presence of EGC in some of the leukocyte fractions examined. A correlation between viral DNA in blood and number or presence of EGC should be investigated in these patients.

The case of patient 1 in Table IV showing nervous system involvement with a high EGC count in CSF and absence of EGC in blood, seems to shed some light on the association between CSF EGC and a HCMV organ syndrome of the nervous system. While EGC enter blood stream and circulate in visceral HCMV disease, in CNS syndromes EGC remain localized in CSF.

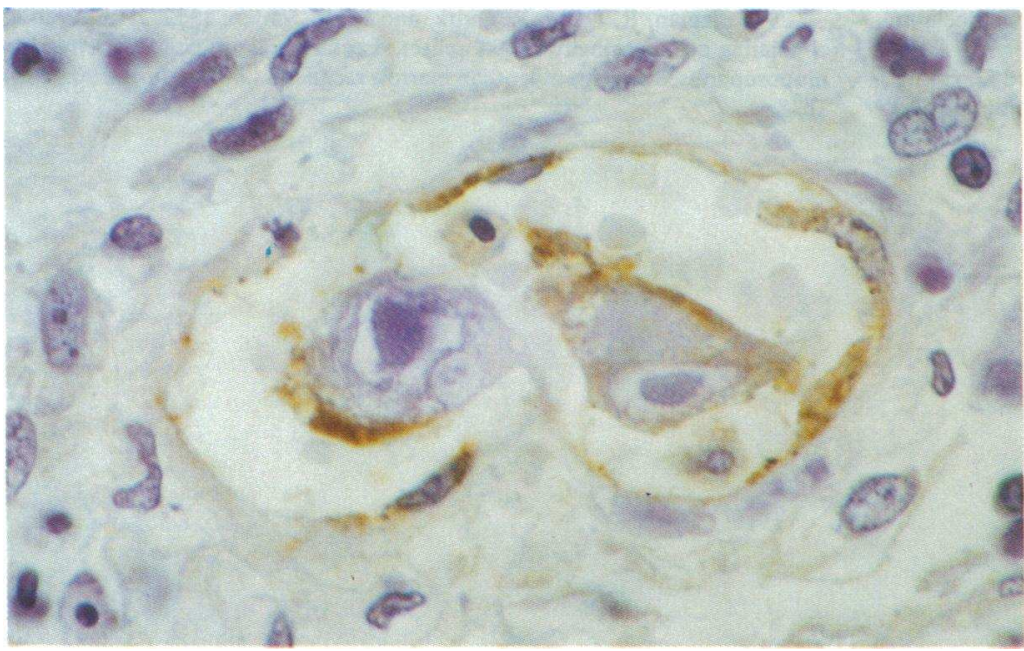

Figure 5. Immunoperoxidase staining of endothelial cells and two giant cells inside the lumen of a small blood vessel from a prostatic tissue section of an AIDS patient. Giant cells are stained at the periphery of the cytoplasm by a mAb to vWf. $\times 1,000$. 
In conclusion, EGC provide a new parameter for the study of the pathogenesis of HCMV infections in immunocompromised patients. In addition, EGC may represent a helpful early clinical marker of HCMV localization, providing the clinician with a quantitative morphological parameter that can be monitored and used to determine antiviral treatment strategy in visceral organ involvement.

\section{Acknowledgments}

We thank Linda D'Arrigo for revision of the English.

This work was partially supported by grants from Ministero della Sanità, Istituto Superiore di Sanità, Progetto Nazionale AIDS 1993, and by the Consiglio Nazionale delle Ricerche, Progetto Finalizzato Biotecnologie e Biostrumentazione.

\section{References}

1. Reichert, C. M., T. S. O'Leary, D. L. Levens, C. L. Simrell, and A. M. Macher. 1983. Autopsy pathology in the acquired immune deficiency syndrome. Am. J. Pathol. 112:357-382.

2. Van der Bij, W., R. Torensma, W. J. Van Son, J. Anema, J. Schirm, A. M. Tegzess, and T. H. The. 1988. Rapid immunodiagnosis of active cytomegalovirus infection by monoclonal antibody staining of blood leukocytes. J. Med. Virol. 25:179-188.

3. Revello, M. G., E. Percivalle, M. Zavattoni, M. Parea, P. Grossi, and G. Gerna. 1989. Detection of human cytomegalovirus immediate-early antigen in leukocytes as a marker of viremia in immunocompromised patients. J. Med. Virol. 29:88-93.

4. Gerna, G., M. G. Revello, E. Percivalle, and F. Morini. 1992. Comparison of different immunostaining techniques and monoclonal antibodies to the lower matrix phosphoprotein (pp65) for optimal quantitation of human cytomegalovirus antigenemia. J. Clin. Microbiol. 30:1232-1237.

5. Gerna, G., M. G. Revello, E. Percivalle, M. Zavattoni, M. Parea, and M. Battaglia. 1990. Quantification of human cytomegalovirus viremia by using monoclonal antibodies to different viral proteins. J. Clin. Microbiol. 28:26812688.

6. Gerna, G., D. Zipeto, E. Percivalle, M. Parea, M. G. Revello, R. Maccario, G. Peri, and G. Milanesi. 1992. Human cytomegalovirus infection of the major leukocyte subpopulations and evidence for initial viral replication in polymorphonuclear leukocytes from viremic patients. J. Infect. Dis. 166:1236-1244.

7. Gerna, G., D. Zipeto, M. Parea, M. G. Revello, E. Silini, E. Percivalle, M. Zavattoni, and G. Milanesi. 1991. Monitoring of human cytomegalovirus infections and ganciclovir treatment in heart transplant recipients by determination of viremia, antigenemia and DNAemia. J. Infect. Dis. 164:488-498.

8. Vaccaro, P. S., L. B. Joseph, L. Titterington, and R. E. Stephens. 1987. Methods for the initiation and maintenance of human endothelial cell culture. Vasc. Surg. 21:391-400.

9. Astaldi, G. C. B., M. C. Janssen, P. Lansdorp, C. Willems, W. P. Zeijlemaker, and F. Oosterhof. 1980. Human endothelial cell supernatant (HECS): a growth factor for hybridomas. J. Immunol. 125:1411-1414.

10. Schlingemann, R. O., G. M. Dingjan, J. J. Emeis, J. Blok, S. O. Warnaar, and D. J. Ruiter. 1985. Monoclonal antibody PAL-E specific for endothelium. Lab. Invest. 52:71-76.

11. Revello, M. G., E. Percivalle, A. Di Matteo, F. Morini, and G. Gerna. 1992. Nuclear expression of the lower matrix protein of human cytomegalovirus in peripheral blood leukocytes of immunocompromised viremic patients. J. Gen. Virol. 73:437-442.

12. Revello, M. G., E. Percivalle, M. Zannino, V. Rossi, and G. Gerna. 1991. Development and evaluation of a capture ELISA method for detection of IgM antibody to the human cytomegalovirus major DNA binding protein. J. Virol. Methods. 35:315-329.

13. Niedobitek, G., T. Finn, H. Herbst, J. Gerdes, L. Grillner, M. Landqvist, B. Zweygberg Wirgart, and H. Stein. 1988. Detection of cytomegalovirus in clinical specimens by in situ hybridization and immunohistochemistry using new monoclonal antibody CCH2: a comparison of methods. J. Clin. Pathol. 41:10051009.

14. Bruggeman, C. A., W. H. M. Debie, A. D. Muller, B. Schutte, and M. C. E. van Dam-Mieras. 1988. Cytomegalovirus alters the von Willebrand factor content in human endothelial cells. Thromb. Haemostasis. 59:264-268.

15. Hashimoto, H., H. Muller, F. Muller, H. L. Schmidts, and H. J. Stutte. 1987. In situ hybridization analysis of cytomegalovirus lytic infection in Kaposi's sarcoma associated with AIDS. Virchow's Arch. Pathol. Anat. 411:441-448.

16. Hinnant, K. L., H. Z. Rotterdam, E. T. Bell, and M. L. Tapper. 1986. Cytomegalovirus infection of the alimentary tract: a clinico-pathologic correlation. Am. J. Gastroenterol. 81:944-950.

17. Melnick, J. L., B. L. Petrie, G. R. Dreesman, J. Burek, C. H. Mc Collum, and M. E. Debakey. 1983. Cytomegalovirus antigen within human arterial smooth muscle cells. Lancet. ii:644-647.

18. Toorkey, C. B., and D. R. Carrigan. 1989. Immunohistochemical detection of an immediate-early antigen of human cytomegalovirus in normal tissues. J. Infect. Dis. 160:741-751.

19. Hendrix, M. G. R., M. M. M. Salimans, C. P. A. Van Boven, and C. A. Bruggeman. 1990. High prevalence of latently present cytomegalovirus in arterial walls of patients suffering from grade III atherosclerosis. Am. J. Pathol. 136:2328.

20. Hendrix, M. G. R., P. H. J. Dormans, P. Kitslaar, F. Bosman, and C. A. Bruggeman. 1989. The presence of HCMV nucleic acids in arterial walls of atherosclerotic and non-atherosclerotic patients. Am. J. Pathol. 134:1151-1157.

21. Hendrix, M. G. R., N. Daemen, and C. A. Bruggeman. 1991. Cytomegalovirus nucleic acid distribution within the human vascular tree. Am. J. Pathol. 138:563-567.

22. Myerson, D., R. C. Hackman, J. A. Nelson, D. C. Ward, and J. K. McDougall. 1984. Widespread presence of histologically occult cytomegalovirus. Hum. Pathol. 15:430-439.

23. Roberts, W. H., J. M. Sneddon, J. Waldman, and R. E. Stephens. 1989. Cytomegalovirus infection of gastrointestinal endothelium demonstrated by simultaneous nucleic acid hybridization and immunohistochemistry. Arch. Pathol. Lab. Med. 113:461-464.

24. Saltzman, R. L., M. R. Quirk, and M. C. Jordan. 1988. Disseminated cytomegalovirus infection. J. Clin. Invest. 81:75-81.

25. Turtinen, L. W., R. Saltzman, M. C. Jordan, and A. T. Haasse. 1987. Interaction of human cytomegalovirus with leukocytes; in vivo analysis by in situ hybridization. Microb. Pathog. 3:287-297.

26. Dankner, W. M., J. A. Mc Cutchan, D. D. Richman, K. Hirata, and S. A. Spector. 1990. Localization of human cytomegalovirus in peripheral blood leukocytes by in situ hybridization. J. Infect. Dis. 161:31-36.

27. Ibanez, C. E., L. Schrier, P. Ghazal, C. Wiley, and J. A. Nelson. 1991. Human cytomegalovirus productively infects primary differentiated macrophages. J. Virol. 65:6581-6588.

28. Lathey, J. L., and S. A. Spector. 1991. Unrestricted replication of human cytomegalovirus in hydrocortisone-treated macrophages. J. Virol. 65:63716375.

29. Saltzman, R. L., M. R. Quirk, and M. C. Jordan. 1992. High levels of circulating cytomegalovirus DNA reflect visceral organ disease in viremic immunosuppressed patients other than marrow recipients. J. Clin. Invest. 90:18321838. 